University of Nebraska - Lincoln

DigitalCommons@University of Nebraska - Lincoln

Faculty Publications, Department of Psychology

Psychology, Department of

$11-1-2004$

\title{
Daily Experiences of Emotions and Social Contexts of Securely and Insecurely Attached Young Adults
}

Julia C. Torquati

University of Nebraska-Lincoln, jtorquati1@unl.edu

Marcela Raffaelli

University of Nebraska-Lincoln, mraffaelli1@unl.edu

Follow this and additional works at: https://digitalcommons.unl.edu/psychfacpub

Part of the Psychiatry and Psychology Commons

Torquati, Julia C. and Raffaelli, Marcela, "Daily Experiences of Emotions and Social Contexts of Securely and Insecurely Attached Young Adults" (2004). Faculty Publications, Department of Psychology. 29.

https://digitalcommons.unl.edu/psychfacpub/29

This Article is brought to you for free and open access by the Psychology, Department of at DigitalCommons@University of Nebraska - Lincoln. It has been accepted for inclusion in Faculty Publications, Department of Psychology by an authorized administrator of DigitalCommons@University of Nebraska - Lincoln. 


\section{Daily Experiences of Emotions and Social Contexts of Securely and Insecurely Attached Young Adults}

\author{
Julia C. Torquati \\ Marcela Raffaelli \\ University of Nebraska, Lincoln
}

This study examined daily emotions and social contexts of young adults who differed in global attachment style (secure vs. insecure). Sixty-nine college students (41\% male, $59 \%$ female) completed self-report measures of attachment and provided timesampling data on moods, companionship, and activities using the experience sampling method. Secure $(n=41)$ and insecure $(n=28)$ young adults spent a similar proportion of time with familiar intimates and alone. Secure individuals reported significantly more positive affect, higher levels of energy, and more connection than insecure individuals when they were alone and higher levels of energy and connection in the context of familiar inti-mates. Secure participants were more likely to report extreme positive emotions, and insecure participants were more likely to report extreme negative emotions, especially when they were alone. Insecure individuals did not report either more labile or flatter emotions than did secure individuals. Results are consistent with the conceptualizationof attachment style as an organizational construct for emotion.

\section{Keywords: attachment; emotions; experience sampling method}

Attachment style has been conceptualized as an organizational construct for emotion, cognition, and behavior (Sroufe \& Waters, 1977). According to attachment theory, affective and cognitive representations of self, others, and relationships, or so-called internal working models, develop from relationship experiences. Expectations regarding social partners are based on representations of past relationship experiences. Emotions experienced in the context of relationships are also based, in part, on representations of past relationship experiences and current expectations regarding social partners. For example, a secure attachment style is characterized by

The authors gratefully acknowledge the support of a grant from the College of Human Resources and Family Sciences Innovation and Excellence Committee.

Published in Journal of Adolescent Research 19:6 (November 2004), pp. 740-758. Copyright (C) 2004 Sage Publications. Used by permission. expectations of availability and acceptance on the part of relationship partners and corresponding positive emotions. On the other hand, uncertainty regarding availability and acceptance by relationship partners characterizes an insecure attachment style, and experiencing associated negative emotions such as worry, loneliness, or discouragement may be more likely.

A considerable body of literature exists examining how attachment style relates to individuals' emotional experiences in social relationships. However, a number of questions remain. First, do people structure their social contexts differently as a function of attachment style? Second, how does attachment style relate to everyday experiences of emotion? Finally, do emotional experiences vary as a function of attachment style and social context? This investigation examines attachment as an organizational construct for everyday emotions in varying social contexts. Research on the social contexts and developmental tasks of young adulthood, and on attachment and emotion, is summarized below to provide the context for hypotheses to be tested.

The social contexts of late adolescence and early adulthood are structured around development of intimate relationships with same-and opposite-sex peers (Buhrmester \& Furman, 1987; Csikszentmihalyi \& Larson, 1987; Larson \& Richards, 1991). Individuals may actively structure their social contexts differently as a function of attachment style because emotions and expectations about relationships differ according to attachment style. However, only one study to date has examined time spent in different social contexts as a function of attachment style. Tidwell, Reis, and Shaver (1996) found that insecure-dismissing individuals were less likely to be involved with a romantic partner and were less likely to interact with individuals of the opposite sex than were secure or insecure-preoccupied individuals. Thus, the first question addressed in this study is whether secure and insecure young adults structure their social time differently.

Differences in emotional experiences have been linked to attachment styles in both self-report and observational studies. For example, insecure late adolescents report more negative affect in their romantic relationships, whereas those with a secure attachment style report more positive affect, trust, and commitment (Simpson, 1990). Feeney and Kirkpatrick (1996) found that autonomic arousal in response to a laboratory separation was higher for insecure than for secure college women. Clinical studies of attachment style also provide evidence of the association between insecure attachment style and emotion dysregulation. Among adolescents, substance abuse, delinquency, and conduct disorder are associated with dismissing attachment style, and affective disorders are associated with preoccupied attachment style (Allen, Hauser, \& Borman-Spurrell, 1996; Kobak, Sudler, 
\& Gamble, 1991; Rosenstein \& Horowitz, 1996). Conversely, secure attachment style is associated with lower levels of depression, anxiety, eating disorders, substance abuse, and personality disorder (Burge et al., 1997; Papini \& Roggman, 1992). Taken together, these studies indicate that emotional experiences of insecure individuals are generally less positive and more negative, especially when using clinical criteria. However, few studies have examined the relationship between attachment style and daily subjective experiences of emotion. Because attachment style is an organizational construct for affect, cognition, and social behavior, it is likely that attachment style is systematically related to everyday emotions in ways that do not warrant a clinical classification.

According to attachment theory, affective and cognitive representations of self and others in relationships, expectations regarding social partners, and emotions experienced in the context of relationships are based in part on representations of past relationship experiences and current expectations regarding social partners. Attachment style reflects a strategy for organizing emotions and cognitions pertaining to self and others. Individuals with a secure attachment style typically have access to positive and negative relationship emotions and memories, so there is relatively little distortion of experience evident (Main \& Goldwyn, 1998). Representations of self and others tend to be positive for such individuals. Individuals with an insecure-dismissing attachment style have typically experienced attachment figures as unavailable, so they have adopted a strategy of "de-activating" the attachment system (Kobak, Cole, Ferenz-Gillies, Fleming, \& Gamble, 1993) as a way of minimizing the importance of attachments and needs for affiliation. A byproduct of this strategy could potentially be a blunting of affective experience, such that emotions may be experienced either as flatter or less positive. Individuals with an insecure-preoccupied attachment style have typically experienced unpredictable availability of attachment figures, so they have adopted a strategy of "activating" the attachment system (Kobak et al., 1993). This strategy is often expressed as hypervigilance because inconsistent availability requires the individual to constantly monitor attachment figures. A byproduct of this strategy may be experiencing more labile emotions because emotional experience may be more dependent on moment-by-moment information derived from monitoring attachment figures rather than from a global perception of the relationship. For example, evidence of availability and caring derived from the frequency of phone calls from attachment figures or gestures of affection (or lack thereof) may have a more potent influence on emotions for a person who is uncertain about others as available and about themselves as loveable.
Because attachment style reflects different strategies for organizing relationship information and emotions, attachment style could affect emotional experience in at least four ways. Insecure individuals could experience (a) less positive emotions or (b) more flat emotions than do secure individuals (reflecting a strategy of minimizing attachment related emotions). Insecure individuals could experience (3) more negative emotions or (4) more variability in their emotions (reflecting a strategy of hypervigilance associated with activation of the attachment system) than do secure individuals. The second question addressed by this study is whether everyday emotional experiences, extreme positive and negative emotions, and emotional variability differ for secure and insecure young adults.

The third question addressed in this study incorporates both attachment style and social context. With respect to daily emotional experiences, is the influence of attachment style limited to activation in the context of perceived threat and in the context of attachment figures, or is attachment style a generalized social orientation? (See Tidwell et al., 1996, for a summary of these two positions.) Research on attachment during young adulthood has focused on romantic relationships. This orientation is based on the assumption that variation in social experiences as a function of attachment style should be evident only in contexts with attachment figures or potential attachment figures. However, researchers have yet to examine how globally or specifically attachment influences emotional experiences: Is attachment style an organizational construct for emotions regardless of context, in the context of attachment relationships only, or in social contexts generally? Research documenting the association between depression, anxiety, and attachment style suggests that the influence of attachment style on emotional experiences transcends social contexts. However, clinical research suffers from the limitation of selection bias because participants in clinical research have sought treatment and been diagnosed with an affective disorder. Moreover, clinical studies are limited by retrospective design, and emotional dispositions assessed by survey instruments or clinical interviews are not contextualized. The current investigation compares daily emotional experiences as a function of attachment style and social context using contemporaneous reports of emotional experiences in a nonclinical sample.

In summary, prior theory and research suggest that individuals with different attachment classifications differ in their emotional experiences. The overall goal of the current study was to explore how securely and insecurely attached young adults experience their daily lives and to examine whether their moment-by-moment mood states reflect global attachment classification. To accomplish these goals, we obtained time-sampling data 
on moods, companionship, and activities from young adults using the experience sampling method (ESM; Csikszentmihalyi \& Larson, 1987). Unlike most self-report methods used in psychological research, the ESM obtains reports of immediate experience, providing moment-by-moment insight into people's emotional reality. Methodological research has demonstrated that ESM is a reliable and valid way of obtaining information from children, adolescents, and adults (Larson, 1989; Larson \& Csikszentmihalyi, 1983; Larson \& Richards, 1994). In the current study, we used ESM snapshots of everyday life to address three research questions:

1. Do young adults structure their social contexts differently as a function of attachment style?

2. How does attachment style relate to everyday experiences of emotion?

3. Do emotional experiences vary as a function of attachment style or social context?

\section{METHOD}

\section{Sample}

Undergraduate students enrolled in social science classes at a midwestern university completed a set of self-report measures and were invited to volunteer for the ESM portion of the study. Two-hundred and fifteen students participated in the survey. Forty-five students volunteered for the ESM task and received $\$ 15$ for their participation. However, students in the social science classes were predominantly female, so the sample was disproportionately female. Therefore, male undergraduate students were recruited from introductory psychology courses and earned research credit for their participation.

Seventy-one students participated in both the survey and ESM tasks. Data from two participants were excluded from analyses because they had no data points in social contexts with familiar intimates. Examination of their diaries indicated that they spent the overwhelming majority of their time at work and in school-related activities. Therefore, sixty-nine participants were included in data analysis.

The analysis sample of 69 participants was similar to the total sample of 215 in terms of ethnicity, year in school, and attachment style $(59.1 \%$ secure for the total sample; $57.1 \%$ secure for the analytic sample). The analytic sample included a higher proportion of males $(41.4 \%)$ than the to- tal sample (29.3\%) because males were purposely recruited to balance the gender composition of the analytic sample.

The 69 participants were predominantly Caucasian (92.6\%). Other ethnic minority groups represented included African American (4.4\%) and Hispanic (2.9\%). Slightly more females (58.6\%) than males (41.4\%) participated. Most participants were freshmen $(39.7 \%)$ or sophomores $(35.3 \%)$, as compared to juniors $(19 \%)$ or seniors $(6 \%)$. All students were young adults.

\section{Procedures}

Participants completed a set of standardized measures and then carried an electronic pager and booklet of self-report forms for 1 week. Using the ESM (Csikszentmihalyi \& Larson, 1987), participants were signaled an average of six or seven times per day for 1 week and were instructed to complete a self-report form every time a signal was received. The self-report form included the date, time, location, people present, activity, and emotions. Signals occurred at random within every 2-hour block of time between the hours of 9:00 a.m. and 9:00 p.m. Participants completed an average of 33.5 forms $($ range $=14-54$; mode $=35.0)$. The participant with 14 reports went out of town for the weekend and received no signals during that time. The ESM study occurred during the semester while classes were in session. No data were collected during spring break or final exams.

\section{Measures}

Attachment style. Standardized measures included an adapted version of the 18-item self-report measure of attachment style developed by Collins and Read (1990). This measure assesses three dimensions of attachment: comfort with closeness (close); comfort depending on others (depend); and anxiety. Participants rated each statement on a scale from 1 (not at all true for me) to 4 (very true for me). The scale was adapted for this research by developing three additional items to assess strategies for organizing attachment-related emotions (Kobak et al., 1993). One item assesses the extent to which attachment relationships are valued ("relationships with others are important to me") and two items assess activation of the attachment system ("sometimes I spend so much time thinking about my relationships with others that I have a hard time getting things done" and "it really bothers me if someone says or does something that I can't figure out"). The relative activation of the attachment system is germane to the third question addressed by this study, which is whether emotional 
experiences vary as a function of attachment style and social context

Because the hypotheses for this study were based on the conceptualization of attachment categories rather than dimensions, Collins's (1996) system for assigning individuals to categories based on continuous dimensional scores was used to categorize individuals. First, close and depend were combined into a single mean score. The item for valuing attachment was included in the close-depend score $(\alpha=.64)$. The activation items were included in the mean anxiety score $(\alpha=.74)$. Individuals scoring 2 or above on each dimension are considered to be high on that dimension, and those scoring below 2 are considered low.

Attachment categories were assigned according to Collins's (1996) system:

1. secure $=$ high close-depend, low anxiety $(n=41)$;

2. preoccupied $=$ high close-depend, high anxiety $(n=25)$;

3. dismissing $=$ low close-depend, low anxiety $(\mathrm{n}=0)$; and

4. fearful $=$ low close-depend, high anxiety $(n=3)$.

This is similar to the proportion of secure individuals in previous studies of attachment in young adulthood (Brennan \& Shaver, 1995; Collins \& Read, 1990; Hazan \& Shaver, 1987; Shaver \& Brennan, 2000; Tidwell et al. 1996). The relatively large proportion of individuals in the preoccupied category, and the absence of individuals in the dismissing category, differs from those found in previous research, but is likely because of the stringent criteria used to determine high and low scores on anxiety. Proportions of the sample were not large enough in each of the separate insecure categories to examine variation as a function of type of insecure attachment. Therefore, all insecure types were combined into a single category for analysis (insecure: $\mathrm{n}=28,41 \%$; secure: $\mathrm{n}=41,59 \%$ ).

Emotional experiences. Following the procedures of the ESM, each time they were signaled during the week, participants provided ratings of 14 emotions on semantic differentials (e.g., happy or unhappy, excited or bored). Pairs of emotion words were placed at opposite ends of lines with five notches, and participants were instructed to mark anywhere on the line. Emotion ratings were coded on a five-point scale, with higher scores indicating more positive emotion.

Composite scores were constructed by computing average scores for three dimensions of emotions: positive affect, energy, and connection. Positive affect and energy have been extensively examined in prior research (Csikszentmihalyi \& Larson, 1987; Larson, Raffaelli, Richards, Ham, \&
Jewell, 1990) and reflect two fundamental aspects of emotional experience (pleasant vs. unpleasant and intensely aroused vs. sleepy; Russell, Lewicka, $\&$ Niit, 1989). The third dimension, connection, was of interest in the present study because socially oriented emotions were theoretically meaningful for testing hypotheses. The positive affect scale $(\alpha=.82)$ included seven semantic differential items (peaceful or irritated, happy or grouchy, hopeful or discouraged, confident or worried, comfortable or tense, fine or miserable, and agreeable or angry). The energy scale $(\alpha=.63)$ included three items (energetic or tired, excited or bored, lively or sleepy). The connection scale $(\alpha=.65)$ included three items (loved or lonely, accepted or rejected, secure or insecure). Reliability analyses revealed that the emotional state of calm did not cluster with the other moods, so it was not included in any of the scales. The positive affect scale was moderately correlated with the connection $(r=.59, p<.01)$ and energy $(r=.51, p<.01)$ scales, but the connection and energy scales were not significantly correlated $(r=.23$, ns). Correlations between the mood scores and attachment dimensions were also examined; the only significant relation was between anxiety and connection $(\mathrm{r}=$ $-.27, \mathrm{p}<.05)$.

In addition to considering mean scores for affect, energy, and connection, we computed the proportion of time participants reported extreme positive and extreme negative scores (i.e., a score of either 1 or 5) on each of the 14 mood states. Prior research has shown that positive and negative emotions are independent, and therefore, group differences in emotional experiences may result from differences in endorsement of either extreme positive or extreme negative moods (Diener \& Eammons, 1985; Larson, 1987; Watson \& Clark, 1984; Watson, Clark, \& Tellegen, 1988). Finally, mean standard deviation scores for affect, energy, and connection were used as a measure of emotional lability within participants, across all self-reports.

Social context. Participants listed people present each time they were signaled. Responses were coded into discrete categories (alone, friends, roommate or roommates, romantic partner, family, and public settings such as class or work), and the percentage of time each person was in each context was computed. Consistent with other time-use studies (e.g., Csikszentmihalyi \& Larson, 1987; Larson et al., 1990), the denominator used for calculating the percentage of time in each category was the total number of self-reports completed by the individual. For the current analysis, two social context groups were formed: alone (32\%) and with same-age familiar intimates (friends, romantic partner, roommates; 33.8\%). Overall, participants reported spending $13.7 \%$ of their time with romantic partners (for those who were dating, $\mathrm{n}=35$ ), $10.5 \%$ of their time with roommates, and 
$16.2 \%$ of their time with friends. Time in other contexts, such as work, class, and other public places (34\%), was grouped into a nonintimate social category for descriptive purposes but was not considered in the main analysis because it does not consistently provide social opportunities. Time spent with families (8.8\%) was omitted from the main analyses because many of the participants were living away from their families, and this representsa constraint on structuring their social time.

\section{Plan of Analysis}

First, we examined whether participants structured their social lives differently as a function of attachment style, focusing on time alone and with familiar intimates. Next, three indicators of daily emotion were compared as a function of attachment style: positive affect, energy, and connection. The influence of attachment style and social context on emotional experience was examined by focusing on time alone and with familiar intimates. We examined three aspects of daily emotional experiences: mean levels of positive affect, energy, and connection; reports of extreme positive and negative moods; and variability of emotions. Because prior research has revealed gender differences in the close relationships of young women and men (e.g., Furman \& Buhrmester, 1992; Feldman, Gowen, \& Fisher, 1998; Winstead, Derlega, \& Rose, 1997), gender effects were examined in all analyses.

\section{RESULTS}

\section{Experiences in Different Social Contexts}

The first question addressed pertained to social behavior, specifically whether secure and insecure individuals structure their social experiences differently. Analysis of variance comparing the proportion of time spent with familiar intimates, $\mathrm{F}(1,67)=0.004$; $\mathrm{ns}$, and alone, $\mathrm{F}(1,67)=0.21$; ns, revealed no differences attributable to attachment style (see Table 1). The social context of familiar intimates was further differentiated by examining time with romantic partners, friends, and roommates. There were no significant differences as a function of attachment style in the proportion of time spent with romantic partners, friends, or roommates, $\mathrm{F}(1,67)=0.03$; ns. Secure individuals were no more likely than were insecure individuals to report that they were currently in a dating relationship, $\chi^{2}=.296, \mathrm{df}=1$, ns. Gender comparisons of time spent alone and with familiar intimates indicated that there was no significant difference between males and females
TABLE 1: Time With Familiar Intimates and Alone as a Function of Attachment Style and Gender

\begin{tabular}{|c|c|c|c|c|c|c|c|c|}
\hline \multirow[b]{2}{*}{ Social Context } & \multicolumn{2}{|c|}{$\begin{array}{l}\text { Secure } \\
(\mathrm{n}=41)\end{array}$} & \multicolumn{2}{|c|}{$\begin{array}{r}\text { Insecure } \\
(\mathrm{n}=28)\end{array}$} & \multicolumn{2}{|c|}{$\begin{array}{c}\text { Men } \\
(n=29)\end{array}$} & \multicolumn{2}{|c|}{$\begin{array}{l}\text { Women } \\
(\mathrm{n}=40)\end{array}$} \\
\hline & $\mathrm{M} \%$ & $\overline{S D} \%$ & $M \%$ & $\overline{\mathrm{SD} \%}$ & $M \%$ & $\overline{\mathrm{SD}} \%$ & $M \%$ & SD \% \\
\hline Alone & 34.0 & 14.6 & 32.3 & 14.9 & 32.3 & 15.8 & 34.0 & 13.9 \\
\hline Familiar intimates & 37.2 & 13.9 & 36.9 & 21.5 & 41.3 & 18.8 & 33.9 & 15.5 \\
\hline Romantic partner ${ }^{a}$ & 14.4 & 10.2 & 12.5 & 10.2 & 13.7 & 11.3 & 13.5 & 9.5 \\
\hline Friends & 17.9 & 14.0 & 14.8 & 16.0 & 21.4 & 15.7 & 13.2 & 13.4 \\
\hline Roommates & 9.5 & 11.1 & 13.5 & 15.4 & 11.2 & 12.6 & 11.0 & 13.5 \\
\hline
\end{tabular}

NOTE: Table shows results based on total self-reports completed.

a. Among subset of respondents who had a romantic partner $(n=33 ; 47.8 \%)$

in time spent alone, $\mathrm{F}(1,67)=0.25$; ns, or with familiar intimates, $\mathrm{F}(1,67)$ $=3.2 ; \mathrm{p}=.08$.

\section{Daily Emotional States Associated With Different Attachment Styles}

The overall relation between attachment style and daily subjective states was examined by conducting multivariate analyses of variance with the three mood scores (positive affect, energy, and connection) as within-subjects repeated measures and attachment style and sex as between-subjects factors. A significant main effect emerged for attachment style, $F(1,65)=$ $12.61, \mathrm{p}<.001$. Follow-up univariate tests indicated that secure individuals reported higher levels of connection than did their insecure peers, $\mathrm{F}(1,66)$ $=8.11 ; \mathrm{p}<.01$, but there were no significant differences in positive affect, $\mathrm{F}(1,66)=1.79$; ns, or energy, $\mathrm{F}(1,66)=2.03$; ns, as a function of attachment style (see Table 2 for means).

To examine emotional states within social contexts, a similar analysis was conducted with the three mood scores (positive affect, energy, and connection) and two contexts (alone and with familiar intimates) as within-subjects repeated measures and attachment style as a between-subjects factor (see Table 3). Significant main effects for mood, $F(1,67)=240.45 ; \mathrm{p}<$ .001 ; context, $\mathrm{F}(1,66)=31.65 ; \mathrm{p}<.001$; and attachment style, $\mathrm{F}(1,66)=$ $14.58, \mathrm{p}<.001$, emerged, as did a significant mood-by-context interaction, $\mathrm{F}(1,66)=12.96 ; \mathrm{p}<.001$, and a trend-level context-by-attachment-style interaction, $\mathrm{F}(1,66)=3.73 ; \mathrm{p}<.06$. The main effect for context indicated that both secure and insecure individuals reported more positive mood states in the context of familiar intimates than when they were alone. Secure individ- 
TABLE 2: Emotional States as a Function of Attachment Style and Gender

\begin{tabular}{|c|c|c|c|c|c|c|c|c|}
\hline \multirow[b]{2}{*}{ Item } & \multicolumn{2}{|c|}{$\begin{array}{l}\text { Secure } \\
(\mathrm{n}=41)\end{array}$} & \multicolumn{2}{|c|}{$\begin{array}{r}\text { Insecure } \\
(\mathrm{n}=28)\end{array}$} & \multicolumn{2}{|c|}{$\begin{array}{c}\text { Men } \\
(\mathrm{n}=29)\end{array}$} & \multicolumn{2}{|c|}{$\begin{array}{l}\text { Women } \\
(\mathrm{n}=40)\end{array}$} \\
\hline & $M$ & $S D$ & $M$ & SD & $M$ & $\mathrm{SD}$ & $\mathrm{M}$ & SD \\
\hline Positive affect & 3.94 & 0.73 & 3.71 & 0.60 & 3.81 & 0.56 & 3.87 & 0.78 \\
\hline Energy & 2.96 & 0.88 & 2.61 & 1.02 & 3.30 & 0.80 & 2.65 & 1.0 \\
\hline Connection & 4.27 & 0.66 & $3.76^{* *}$ & * 0.82 & 4.05 & 0.65 & 4.08 & 0.85 \\
\hline
\end{tabular}

${ }^{*} p<.05 .{ }^{* *} p<.01 .{ }^{* * *} p<.001$.

TABLE 3: Emotional States in Different Social Contexts as a Function of Attachment Style and Gender

\begin{tabular}{|c|c|c|c|c|c|c|c|c|}
\hline \multirow[b]{3}{*}{ Affect } & \multicolumn{4}{|c|}{ Alone } & \multicolumn{4}{|c|}{ With Familiar Intimates } \\
\hline & \multicolumn{2}{|c|}{ Secure } & \multicolumn{2}{|c|}{ Insecure } & \multicolumn{2}{|c|}{ Secure } & \multicolumn{2}{|c|}{ Insecure } \\
\hline & 3.90 & .38 & $3.54^{* *}$ & .56 & 4.0 & .44 & 3.80 & .63 \\
\hline Energy & 3.01 & .41 & $2.54^{* * *}$ & .47 & 3.38 & .43 & $3.10^{\circ}$ & .61 \\
\hline Connection & 4.18 & .45 & $3.68^{* * *}$ & .66 & 4.31 & .45 & $4.02^{\circ}$ & .64 \\
\hline
\end{tabular}

${ }^{*} p<.05 .{ }^{* *} p<.01 .{ }^{* * *} p<.001$.

NOTE: $n=41$ for secure; $n=28$ for insecure.

uals reported higher levels of positive affect, energy, and connection when they were alone and higher energy and connection when they were with familiar intimates than did insecure individuals.

Additional analyses were conducted to examine whether the differences by attachment style resulted from differential experiences of extreme positive emotions as opposed to extreme negative emotions. Independent samples $t$ tests were used to compare the mean percentage of extreme positive and extreme negative emotions reported by securely and insecurely attached individuals. Overall, securely attached individuals were more likely to say they felt extremely agreeable, comfortable, excited, loved, secure, and calm, as compared to insecure individuals (see Table 4). In the company of familiar intimates, secure individuals were more likely than were insecure individuals to report feeling comfortable, excited, loved, secure, and calm; when alone, they were more likely to feel agreeable, comfortable, happy, excited, loved, and secure.

In contrast, insecurely attached individuals were more likely to report extreme negative moods than were their securely attached peers, particularly when alone. Insecure individuals more frequently reported that they were very tired, sleepy, lonely, and nervous overall (see Table 5). There were no
TABLE 4: Percentage Endorsement of Extreme Positive Emotions in Different Contexts by Attachment Style

\begin{tabular}{|c|c|c|c|c|c|c|}
\hline \multirow[b]{2}{*}{ Item } & \multicolumn{2}{|c|}{ Overall } & \multicolumn{2}{|c|}{ Familiar Intimates } & \multicolumn{2}{|c|}{ Alone } \\
\hline & $\begin{array}{l}\text { Secure } \\
\text { M \% }\end{array}$ & $\begin{array}{c}\text { Insecure } \\
\mathrm{M} \%\end{array}$ & $\begin{array}{c}\text { Secure } \\
M \%\end{array}$ & $\begin{array}{c}\text { Insecure } \\
\text { M \% }\end{array}$ & $\begin{array}{c}\text { Secure } \\
\text { M \% }\end{array}$ & $\begin{array}{c}\text { Insecure } \\
\text { M \% }\end{array}$ \\
\hline \multicolumn{7}{|l|}{ Positive affect } \\
\hline Agreeable & 49.3 & $37.4^{*}$ & 54.7 & 40.6 & 50.1 & $32.2^{* *}$ \\
\hline Comfortable & 51.6 & $40.2^{*}$ & 58.3 & $41.9^{*}$ & 52.7 & $38.2^{*}$ \\
\hline Confident & 21.4 & 18.1 & 24.6 & 22.1 & 21.7 & 15.3 \\
\hline Fine & 31.2 & 30.0 & 35.2 & 34.1 & 30.7 & 26.2 \\
\hline Happy & 41.0 & 32.7 & 50.4 & 39.3 & 40.3 & $25.3^{* *}$ \\
\hline Hopeful & 21.2 & 15.4 & 25.7 & 17.3 & 21.9 & 14.7 \\
\hline Peaceful & 24.2 & 21.8 & 26.4 & 23.8 & 25.8 & 23.7 \\
\hline \multicolumn{7}{|l|}{ Energy } \\
\hline Energetic & 8.3 & 8.6 & 10.3 & 11.3 & 7.2 & 5.7 \\
\hline Excited & 21.7 & $12.1^{* *}$ & 28.5 & $14.2^{* *}$ & 16.0 & $6.5^{* *}$ \\
\hline Lively & 11.2 & 8.6 & 13.5 & 10.3 & 10.9 & 7.0 \\
\hline \multicolumn{7}{|l|}{ Connection } \\
\hline Accepted & 32.1 & 22.6 & 34.7 & 27.4 & 30.0 & 19.5 \\
\hline Loved & 50.8 & $28.0^{* *}$ & 57.6 & $35.8^{* *}$ & 48.9 & $22.8^{* *}$ \\
\hline Secure & 58.5 & $36.4^{* *}$ & 62.3 & $41.5^{*}$ & 55.0 & $33.3^{* *}$ \\
\hline Calm & 54.8 & $42.1^{*}$ & 60.1 & $40.6^{*}$ & 57.2 & 50.1 \\
\hline
\end{tabular}

NOTE: Mean percentage of times when participants reported a score of 5 (extremely positive) for each emotional state.

${ }^{*} p<.05 ;{ }^{* *} p<.01$.

differences between secure and insecure individuals in the endorsement of extreme negative emotions in the context of familiar intimates. However, when they were alone, insecurely attached individuals were significantly more likely to report being worried, miserable, grouchy, discouraged, irritated, tired, bored, sleepy, lonely, and nervous than were secure individuals.

Additional analyses (not shown) were conducted to determine whether the differences in emotions as a function of attachment style resulted from differences in the types of activities participants engaged in (i.e., sports, leisure, watching television). Analyses of variance examining the proportion of time spent in different activities indicated no significant differences as a function of attachment style or sex.

\section{Emotional Variability}

Variability of emotions was compared as a function of attachment style by computing mean standard deviation scores for positive affect, energy, 
TABLE 5: Percentage Endorsement of Extreme Negative Emotions in Different Contexts by Attachment Style

\begin{tabular}{|c|c|c|c|c|c|c|}
\hline \multirow[b]{2}{*}{ Item } & \multicolumn{2}{|c|}{ Overall } & \multicolumn{2}{|c|}{ Familiar Intimates } & \multicolumn{2}{|c|}{ Alone } \\
\hline & $\begin{array}{c}\text { Secure } \\
\text { M \% }\end{array}$ & $\begin{array}{c}\text { Insecure } \\
\mathrm{M} \%\end{array}$ & $\begin{array}{c}\text { Secure } \\
\text { M \% }\end{array}$ & $\begin{array}{c}\text { Insecure } \\
\mathrm{M} \%\end{array}$ & $\begin{array}{c}\text { Secure } \\
\text { M \% }\end{array}$ & $\begin{array}{c}\text { Insecure } \\
\mathrm{M} \%\end{array}$ \\
\hline \multicolumn{7}{|l|}{ Positive affect } \\
\hline Angry & 0.95 & 1.6 & 0.77 & 1.6 & 0.57 & 1.4 \\
\hline Tense & 2.8 & 5.3 & 1.8 & 4.1 & 2.9 & 7.4 \\
\hline Worried & 5.2 & 6.3 & 3.6 & 6.6 & 3.0 & $11.8^{*}$ \\
\hline Miserable & 2.4 & 2.9 & 3.6 & 4.2 & 1.2 & $4.2^{*}$ \\
\hline Grouchy & 1.8 & 3.4 & 1.5 & 2.9 & 1.5 & $5.2^{*}$ \\
\hline Discouraged & 4.1 & 5.8 & 4.3 & 5.6 & 2.9 & $10.0^{*}$ \\
\hline Irritated & 6.6 & 9.8 & 4.1 & 9.1 & 3.2 & $13.4^{* *}$ \\
\hline \multicolumn{7}{|l|}{ Energy } \\
\hline Tired & 16.7 & $23.1^{*}$ & 12.7 & 17.2 & 22.3 & $35.3^{*}$ \\
\hline Bored & 2.8 & 6.0 & 2.1 & 4.1 & 1.7 & $7.1^{*}$ \\
\hline Sleepy & 13.4 & $20.2^{*}$ & 9.3 & 13.9 & 17.8 & $32.8^{* *}$ \\
\hline \multicolumn{7}{|l|}{ Connection } \\
\hline Rejected & 1.2 & 1.6 & 1.4 & 3.3 & 1.10 & 3.2 \\
\hline Lonely & 0.3 & $3.4^{*}$ & 0.2 & 1.5 & 0.57 & $5.9^{*}$ \\
\hline Insecure & 0.6 & 1.4 & 1.6 & 1.5 & 0.22 & 1.5 \\
\hline Nervous & 1.5 & $3.6^{*}$ & 1.0 & 2.0 & 1.00 & $6.9^{*}$ \\
\hline
\end{tabular}

NOTE: Mean percentage of times when participants reported a score of 1 (extremehy negative) for each emotional state.

${ }^{*} p<.05 .{ }^{* *} p<.01$.

and connection. Analyses of variance indicated no significant main effects of attachment style (for positive affect, $F[1,67]=0.52$; for energy, $F[1,67]$ $=0.84$; for connection, $\mathrm{F}[1,67]=1.32$; all ns), suggesting that secure and insecure individuals do not differ in the lability of their emotional experiences. Sex differences did emerge; women were more variable than men in their reports of positive affect, $\mathrm{F}(1,67)=13.62$, $\mathrm{p}<.001$, and energy, $\mathrm{F}(1$, $67)=13.63, p<.001$. Men and women did not differ in variability of connection, $\mathrm{F}(1,67)=2.61$, ns.

\section{DISCUSSION}

This study examined the emotional experiences and social contexts of securely and insecurely attached college students. Consistent with the conceptualization of attachment style as an organizational construct for emotional experiences, secure and insecure young adults differed in their emotional experiences in everyday settings. Because the study involved the collection of multiple mood ratings over the course of an entire week, it is likely that the findings reflect a general pattern of emotional experiences, suggesting that attachment style has a generalized influence on emotional experiences.

Differences in emotional experiences did not result from differences in daily social experiences attributable to attachment style. In addressing our first research question, we found that secure and insecure college students spent a similar proportion of time alone and with familiar intimates (romantic partners, friends, roommates). We also found that secure individuals were no more likely to be in a romantic relationship than were insecure individuals. There is little prior research on the social contexts of individuals who differ in attachment classification. Tidwell and colleagues (1996) reported that avoidant individuals spent less time with romantic partners, in contrast to the current finding of no differences in social interactions based on attachment style. There are two possible reasons for this discrepancy. First, in the current study, most of the insecure participants fell into the preoccupied category, with insufficient numbers in other insecure attachment classifications; thus, we were unable to examine differences as a function of subtype of insecure attachment. Second, it is possible that the college setting imposes a certain degree of structure on the social lives of students, resulting in similarities in social context that do not reflect choice but rather the types of living situations (e.g., dorms, shared apartments) in which students typically live. Additional research is needed to examine the question of whether people structure their social lives differently as a function of attachment style.

The second research question examined linkages between attachment style and everyday experiences of emotion. It was hypothesized that attachment style could affect emotional experience in four ways: insecure individuals could experience less positive emotions than secure individuals; insecure individuals could experience more negative emotions; insecure individuals could experience flatter emotions; and insecure individuals could experience more variability in their emotions. We examined emotional experiences both overall and by social context (alone and with familiar intimates). Overall, secure individuals reported a higher degree of connection (a measure of the extent to which individuals feel loved, accepted, and secure) than did their insecure peers, but no differences in the two other global emotion measures of positive affect and energy emerged. Moreover, secure individuals were more likely than insecure individuals to endorse extreme positive emotions, whereas insecure individuals were more likely to endorse extreme negative emotions. Thus, secure individuals experience more positive daily emotions and more frequent extreme positive emotions than insecure individuals. This is consistent with the findings of Tidwell 
et al. (1996) and Collins (1996). The two attachment groups did not differ in emotional variability, suggesting that insecure individuals do not experience either more flat or labile emotional states than secure do individuals.

More fine-grained analyses within social contexts revealed that insecure individuals tended to report particularly low moods when they were alone. Insecure individuals reported lower levels of positive affect, energy, and connection when they were alone than did secure individuals; smaller (but still significant) differences in energy and connection emerged in the context of familiar intimates. The emotional differences between secure and insecure individuals resulted from differences in both extreme positive and extreme negative moods. Secure individuals were more likely than insecure individuals to rate their moods at the extreme positive end of the scale both when alone and with familiar intimates. For example, securely attached individuals were more likely to report extreme feelings of being loved, secure, comfortable, and excited. In addition, insecure individuals more frequently reported extreme negative emotions when they were alone (but not in the company of familiar intimates). When alone, insecure individuals were 10 times more likely to report feeling extremely lonely, more than 4 times as likely to report feeling extremely irritated, and more than 3 times as likely to report feeling extremely discouraged, worried, or miserable than were secure individuals.

The fact that differences in emotions were more pronounced when respondents were alone expands our understanding of the relation between attachment style and emotional experiences. The pattern of results suggests that attachment style has a generalized influence on emotional experiences that transcends social context. Secure and insecure individuals may differ in the extent to which feelings of attachment are maintained when potential attachment figures are absent. Insecure individuals may need the presence of others to experience connection (i.e., feel loved, accepted, and secure), whereas secure individuals can maintain positive moods when they are alone, presumably because their internal working models of self, relationships, others, and the social world in general is positive, stable, and global. Evidence of a generalized influence of attachment style on daily experiences of emotion is consistent with a more generalized influence found in clinical studies and in studies of coping and attachment (e.g., Allen et al., 1996; Kobak et al., 1991; Rosenstein \& Horowitz, 1996).

Limitations of this study point to future directions for research. First, attachment style and daily experiences of emotion were assessed using selfreport instruments; replication of findings using the Adult Attachment Interview (Main \& Goldwyn, 1998) and other measures not derived from self-reports would further validate results of this study. Second, the sam- ple was not large enough to examine subtypes of insecure attachment, and most of the insecure participants fell into the preoccupied group. Purposive sampling of subtypes of insecure attachment would permit comparison of dismissing, fearful, and preoccupied attachment styles. Third, refinement of the diary report to include more finely tuned measures of social context and ratings of perceived closeness should permit more precise comparisons of familiar intimates. This study relied on open-ended descriptions of companions, so a response of friends does not differentiate between acquaintances and best friends, for example. Combining ratings of closeness, such as those used by Tidwell et al. (1996), with ESM may be an effective strategy to address this limitation. Fourth, examination of emotional experiences with family was limited because many participants were living away from their family of origin. Attachment develops primarily within the family of origin, so this is an important context within which to examine the influence of attachment on emotional experiences. Fifth, the measure of connection as a dimension of emotional experience was developed specifically for this research. Mean differences as a function of attachment style suggest that it is a valid measure, but further validation is necessary. Finally, the ESM uses contemporaneous measures of subjective emotional experience but is still subject to the limitations of self-report measures. Alternative data collection procedures (e.g., observations, measures of autonomic arousal, or involvement of multiple reporters) are needed to address this issue.

Despite these limitations, this study offers several unique contributions to the study of attachment and emotion. First, this investigation is one of only a few studies using contemporaneous reports of emotion. Time-sampling data offer several strengths: They are less subject to problems of recall; multiple data points are gathered for each participant; and self-reports of emotion and experience are contextualized. Second, this study examined how attachment influences emotional experiences when alone and with familiar intimates. Previous research has examined the influence of attachment by using global survey instruments without incorporating context or by using contemporaneous reports of experiences in social contexts but not alone (Tidwell et al., 1996). These data address the question of whether attachment style has a global, pervasive influence on daily emotional experiences or if attachment style influences emotional experiences only in social contexts.

Based on the findings, secure and insecure young adults differ in their emotional experiences both in interpersonal contexts and alone. Securely attached individuals experienced more positive average moods and reported more extreme positive emotions than did insecure individuals, regardless of social context, whereas insecure individuals reported more extreme neg- 
ative emotions, especially when they were alone. This research adds support to the conceptualization of attachment style as an organizational construct for emotion.

\section{REFERENCES}

Allen, J. P., Hauser, S. T., \& Borman-Spurrell, E. (1996). Attachment theory as a framework for understanding sequelae of severe adolescent psychopathology: An 11-year follow-up study. Journal of Consulting and Clinical Psychology, 64(2), 254-263.

Brennan, K., \& Shaver, P. R. (1995). Dimensions of adult attachment, affect regulation, and romantic relationship functioning. Personality \& Social Psychology Bulletin, 21(3), 267־-283.

Buhrmester, D., \& Furman, W. (1987). The development of companionship and intimacy. Child Development, 58, 1101-1113.

Burge, D., Hammen, C., Davila, J., Daley, S., Paley, B., Lindberg, N., et al. (1997). The relationship between attachment cognitions and psychological adjustment in late adolescent women. Development and Psychopathology, 9, 151-167.

Collins, N. L. (1996). Working models of attachment: Implications for explanation, emotion, and behavior. Journal of Personality and Social Psychology, 71, 810-832.

Collins, N. L., \& Read, S. J. (1990). Adult attachment, working models, and relationship quality in dating couples. Journal of Personality and Social Psychology, 58, 644-663.

Csikszentmihalyi, M., \& Larson, R. W. (1987). The experience sampling method. Journal of Nervous and Mental Disease, 175, 526-536.

Diener, E., \& Eammons, R. A. (1985). The independence of positive and negative affect. Journal of Personality and Social Psychology, 47, 1105-1117.

Feeney, B. C., \& Kirkpatrick, L. A. (1996). The effects of adult attachment and presence of romantic partners on physiological responses to stress. Journal of Personality and Social Psychology, 70, 255-270.

Feldman, S. S., Gowen, L. K., \& Fisher, L. (1998). Family relationships and gender as predictors of romantic intimacy in young adults: A longitudinal study. Journal of Research on Adolescence, 8, 263-286.

Furman, E., \& Buhrmester, D. (1992). Age and sex differences in perceptions of networks of personal relationships. Child Development, 63, 103-115.

Hazan, C., \& Shaver, P. (1987). Romantic love conceptualized as an attachment process. Journal of Personality and Social Psychology, 52, 511-524.

Kobak, R., Cole, H., Ferenz-Gillies, R., Fleming, W., \& Gamble, W. (1993). Attachment and emotion regulation during mother-teen problem solving: A control theory analysis. Child Development, 64, 231-245.

Kobak, R., Sudler, N., \& Gamble, W. (1991). Attachment and depressive symptoms during adolescence: A developmental pathways analysis. Development and Psychopathology, 3, 461 $\neg 474$.

Larson, R. W. (1987). On the independence of positive and negative affect within hourto-hour experience. Motivation and Emotion, 11, 145-156.

Larson, R. W. (1989). Beeping children and adolescents: A method for studying time use and daily experience. Journal of Youth and Adolescence, 18, 511-530.
Larson, R. W., \& Csikszentmihalyi, M. (1983). The experience sampling method. In H. T. Reis (Ed.), Naturalistic approaches to studying social interaction (pp. 41-56). San Francisco: Jossey-Bass.

Larson, R. W., Raffaelli, M., Richards, M. H., Ham, M., \& Jewell, L. (1990). Ecology of depression in late childhood and early adolescence: A profile of daily states and activities. Journal of Abnormal Psychology, 99, 92-102.

Larson, R. W., \& Richards, M. H. (1991). Daily companionship in late childhood and early adolescence: Changing developmental contexts. Child Development, 62, 284-300.

Larson, R. W., \& Richards, M. H. (1994). Divergent realities: The emotional lives of mothers, fathers, and adolescents. New York: Basic Books.

Main, M., \& Goldwyn, R. (1998). Adult attachment scoring and classification systems (Draft manual, Version 6.1). Berkeley: University of California Press.

Papini, D. R., \& Roggman, L. A. (1992). Adolescent perceived attachment to parents in relation to competence, depression, and anxiety: A longitudinal study. Journal of Early Adolescence, 12, 420-440

Rosenstein, D. S., \& Horowitz, H. A. (1996). Adolescent attachment and psychopathology. Journal of Consulting and Clinical Psychology, 64(2), 244-253.

Russell, J. A., Lewicka, M., \& Niit, T. (1989). A cross-cultural study of a circumplex model of affect. Journal of Personality and Social Psychology, 57, 848-856.

Shaver, P. R., \& Brennan, K. (2000). Dimensions of adult attachment, affect regulation, and romantic relationship functioning. Personality \& Social Psychology Bulletin, 21(3), 267-283.

Simpson, J. A. (1990). Influence of attachment styles on romantic relationships. Journal of Personality and Social Psychology, 59, 971-980.

Sroufe, L., \& Waters, E. (1977). Attachment as an organizational construct. Child Development, 48, 1184-1199.

Tidwell, M. O., Reis, H. T., \& Shaver, P. R. (1996). Attachment, attractiveness, and social interaction: A diary study. Journal of Personality and Social Psychology, 71, 729-745.

Watson, D., \& Clark, L. A. (1984). Negative affectivity: The disposition to experience aversive emotional states. Psychological Bulletin, 96, 465-490.

Watson, D., Clark, L. A., \& Tellegen, A. (1988).Development and validation of brief measures of positive and negative affect: The PANAS scales. Journal of Personality and Social Psychology, 35, 742-754.

Winstead, B. A., Derlega, V. J., \& Rose, S. (1997). Gender and close relationships. Thousand Oaks, CA: Sage.

Julia C. Torquati, Ph.D., is an associate professor in family and consumer science and research coordinator for the Ruth Staples Child Development Lab. Her research focuses on the role of relationships in development, including investigation of the associations between attachment style and coping behaviors in adults and preschool-age children, children's relationships with their parents and teachers, and relationships between adolescent parents and their children. She is a member of the Midwest Child Care Research Consortium, which is investigating teacher, parent, and observer perceptions of qualities of early care and education. She teaches courses on adolescent development, parent-child relations, children's social development, and environmental education in early childhood. 
Marcela Raffaelli is an associate professor at the University of Nebraska, Lincoln, where she holds a joint appointment in the Department of Psychology and the Institute for Ethnic Studies. She received her Ph.D. in psychology and human development from the University of Chicago and was a postdoctoral researcher at Johns Hopkins University and Rutgers University. Current research projects focus on cultural and familial in-

fluences on adolescent and young adult development. 